\title{
Cefixime use in children: When and why
}

$\mathrm{T}$ HIRD-GENERATION CEPHALOSPORINS ARE USED WIDELY FOR the treatment of a variety of infections in children. Cefixime is currently the only third-generation cephalosporin for oral administration in Canada, and was licensed in 1990.

\section{PHARMACOLOGY}

Gastrointestinal absorption is incomplete (about 40 to $50 \%$ is absorbed). The oral suspension is more rapidly and completely absorbed than the tablets. The elimination half-life is about $3 \mathrm{~h}$ (1). The drug is not appreciably metabolized, and 25 to $50 \%$ of the dose is excreted in the urine within $24 \mathrm{~h}$. The recommended dosage for children is $8 \mathrm{mg} / \mathrm{kg} /$ day orally, once daily or in two divided doses.

\section{ANTIMICROBIAL ACTIVITY}

Cefixime has good activity against group $A$ and group $B$ streptococci and Streptococcus pneumoniae. However, viridans streptococci and groups C, F and G streptococci are only moderately susceptible, while Staphylococcus aureus, coagulasenegative staphylococci, enterococci and Listeria monocytogenes are resistant (1).

Cefixime has excellent activity against Neisseria gonorrhoeae, Moraxella catarrhalis, Haemophilus influenzae (including beta-lactamase producing strains of these bacteria), and against Gram-negative bacilli such as Escherichia coli, Klebsiella pneumoniae, Proteus mirabilis, as well as Salmonella and Shigella species (1). However, it has poor activity against Pseudomonas and Serratia species, Enterobacter cloacae and Citrobacter freundii.

Cefixime is not effective against anaerobes.

\section{CLINICAL TRIALS IN CHILDREN}

Clinical trials have shown that cefixime is comparable with amoxicillin and cefaclor for the treatment of acute otitis media in children two months to 13 years of age (2-6). S pneumoniae was the most common pathogen, followed by nontypeable $H$

All material presented in Pediatric Infectious Disease Notes has been reviewed and approved by the chairperson, Canadian Paediatric Society Board and representative members of the Canadian Paediatric Society Committee on Infectious Diseases and Immunization

Correspondence and reprints: Infectious Diseases and Immunization Committee, Canadian Paediatric Society, 401 Smyth Road, Ottawa, Ontario K1H 8L1. Telephone 613-737-2728, Fax 613-737-2794 influenzae and $M$ catarrhalis. Cefixime was very effective in treating cases due to $H$ influenzae and $M$ catarrhalis (75 to $100 \%$ cure or improvement), which was comparable with or better than either amoxicillin or cefaclor $(2,3,5)$. Cefixime had a slightly lower efficacy in cases caused by $S$ pneumoniae compared with amoxicillin $(2,3)$. In one study, a number of cefixime failures were due to $S$ pneumoniae (2), perhaps supporting an experimental observation that cefixime required a longer duration (up to 10 days) compared with amoxicillin to eradicate pneumococcus from the middle ear (6).

One study of streptococcal pharyngitis in children four to 12 years of age reported that cefixime was better at both eradicating and preventing recurrences of group A streptoccus compared with penicillin $\mathrm{V}(7)$. The reasons for this are not understood.

Studies have shown cefixime to be effective for the treatment of urinary tract infection (with success rate comparable with that of trimethoprim-sulfamethoxazole [8]), Salmonella typhi infection (9) and multiresistant Shigella species gastroenteritis (10) in children. Oral cefixime was as effective as intramuscular ceftriaxone in the treatment of uncomplicated gonorrhea in teenagers and young adults (11).

\section{ADVERSE EFFECTS}

The adverse effects of cefixime are generally mild and transient. In controlled trials comparing cefixime with amoxicillin, the most notable effect was diarrhea, occurring in about $15 \%$ of children on cefixime and about $8 \%$ on amoxicillin (1). Diarrhea was usually mild, developed within four days of treatment and resolved on discontinuation of cefixime (12). Severe diarrhea and/or pseudomembranous colitis were reported in fewer than $2 \%$ of patients. Drug hypersensitivity reactions also occurred rarely.

\section{CEFIXIME USE IN CHILDREN}

Although cefixime is an effective antibiotic in many situations, less expensive and equally effective alternatives are frequently available. The following are guidelines on the use of cefixime in children:

- For otitis media, since $S$ pneumoniae is the most common bacterial pathogen, cefixime does not offer any advantages over less expensive agents such as amoxicillin, trimethoprim-sulfamethoxazole and erythromycin-sulfisoxazole. While beta-lactamase 
producing $H$ influenzae and $M$ catarrhalis are also common pathogens in otitis media, amoxicillin has been found to be effective even in many of these cases.

- For streptococcal pharyngitis, penicillin $\mathrm{V}$ remains the treatment of choice. Only penicillin has been studied and reported effective in preventing rheumatic fever. However, suitable antibiotic alternatives include erythromycin and cephalosporins. Cefixime and other less expensive first- and second-generation cephalosporins are effective in treating streptococcal sore throat.

- There are as yet insufficient published controlled studies that show cefixime to be effective for the treatment of children with sinusitis, 'bronchitis' or pneumonia. However, its antimicrobial spectrum does include the bacterial pathogens that commonly cause sinusitis and pneumonia in children.

- For urinary tract infection, cefixime offers little advantage over less expensive agents such as amoxicillin, trimethoprim-sulfamethoxazole and nitrofurantoin. However, cefixime can be used to treat urinary pathogens that are resistant to those antibiotics, but susceptible to cefixime.

- Single-dose cefixime is effective in treating uncomplicated gonorrhea infections, while longer duration is required to treat pelvic inflammatory disease caused partly by $N$ gonorrhoeae. However, it is controversial whether cefixime is effective in treating pharyngeal gonorrhea.

- Cefixime is effective for treatment of young children (where quinolone antibiotics are contra- indicated) with gastroenteritis caused by Salmonella and Shigella species that are resistant to traditional antibiotics such as amoxicillin and trimethoprim- sulfamethoxazole. However, it is not known whether resistance will eventually develop in these pathogens with the increasing use of cefixime.

- Preliminary evidence suggests that switching to oral cefixime may be an effective alternative (after initial parenteral antibiotic therapy) in preventing the occurrence of serious Gram-negative infections in oncology patients recovering from febrile neutro- penia (13). However, controlled studies are awaited.

\section{REFERENCES}

1. Leggett NJ, Caravaggio C, Rybak MJ. Cefixime. DICP Ann Pharmacother 1990;24:489-95.

2. Johnson CE, Carlin SA, Super DM, et al. Cefixime compared with amoxicillin for treatment of acute otitis media. J Pediatr 1991;119:117-22.

3. Howie VM, Owen MJ. Bacteriologic and clinical efficacy of cefixime compared with amoxicillin in acute otitis media. Pediatr Infect Dis J 1987;6:989-91.

4. Harrison CJ, Chartrand SA, Pinichero ME. Microbiologic and clinical aspects of a trial of once daily cefixime compared with twice daily cefaclor for treatment of acute otitis media in infants and children. Pediatr Infect Dis J 1993;12:62-9.

5. Rodriguez WJ, Khan W, Sait T, et al. Cefixime vs cefaclor in the treatment of acute otitis media in children: a randomized, comparative study. Pediatr Infect Dis J 1993;12:70-4.

6. Bluestone CD. Review of cefixime in the treatment of otitis media in infants and children. Pediatr Infect Dis J 1993;12:75-82.

7. Block SL, Hedrick JA, Tyler RD. Comparative study of the effectiveness of cefixime and penicillin $V$ for the treatment of streptococcal pharyngitis in children and adolescents. Pediatr Infect Dis J 1992;11:919-25.

8. Dagan R, Einhorn M, Lang R, et al. Once daily cefixime compared with twice daily trimethoprim/ sulfamethoxazole for treatment of urinary tract infection in infants and children. Pediatr Infect Dis J 1992;11:198-203.

9. Bhutta ZA, Khan IA, Molla AM. Therapy of multidrug-resistant typhoid fever with oral cefixime vs intravenous ceftriaxone. Pediatr Infect Dis J 1994;13:990-4.

10. Ashkenazi S, Amir J, Waisman $\mathrm{Y}$, et al. A randomized, double-blind study comparing cefixime and trimethoprim-sulfamethoxazole in the treatment of childhood shigellosis. J Pediatr 1993:123:817-21.

11. Hunter Handsfield $\mathrm{H}$, McCormack WM, Hook EW, et al. A comparison of single-dose cefixime with ceftriaxone as the treatment for uncomplicated gonorrhea. N Engl J Med 1991;325:1337-41.

12. Tally FP, Desjardins RE, McCarthy EF, Cartwright K. Safety profile of cefixime. Pediatr Infect Dis J 1987;6:976-80.

13. Lau RC, King SM, Richardson SE. Early discharge of pediatric febrile neutropenic cancer patients by substitution of oral for intravenous antibiotics. Pediatr Hematol Oncology1994;11:417-21. 


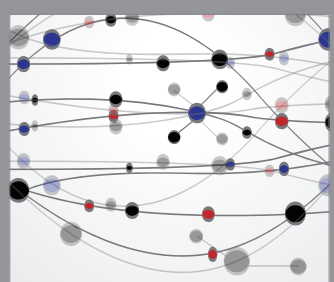

The Scientific World Journal
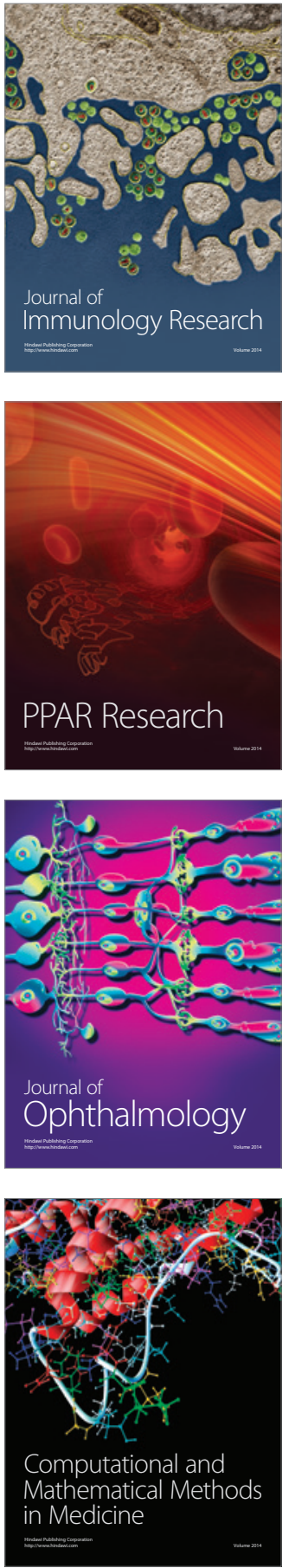

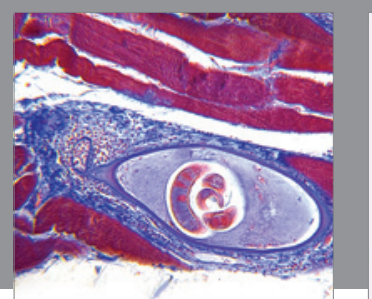

Gastroenterology Research and Practice

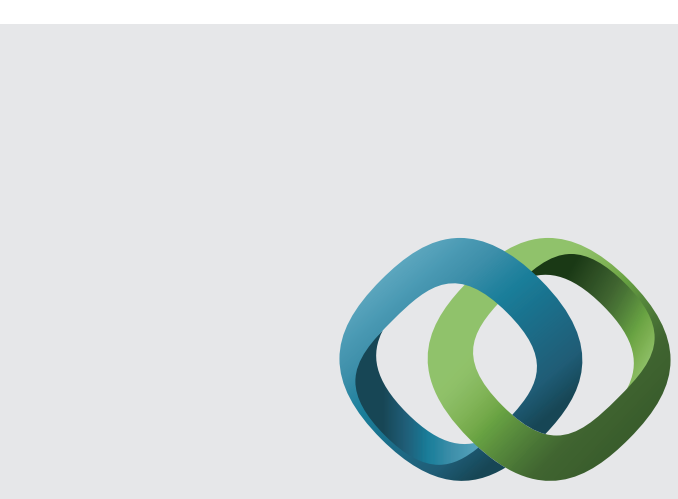

\section{Hindawi}

Submit your manuscripts at

http://www.hindawi.com
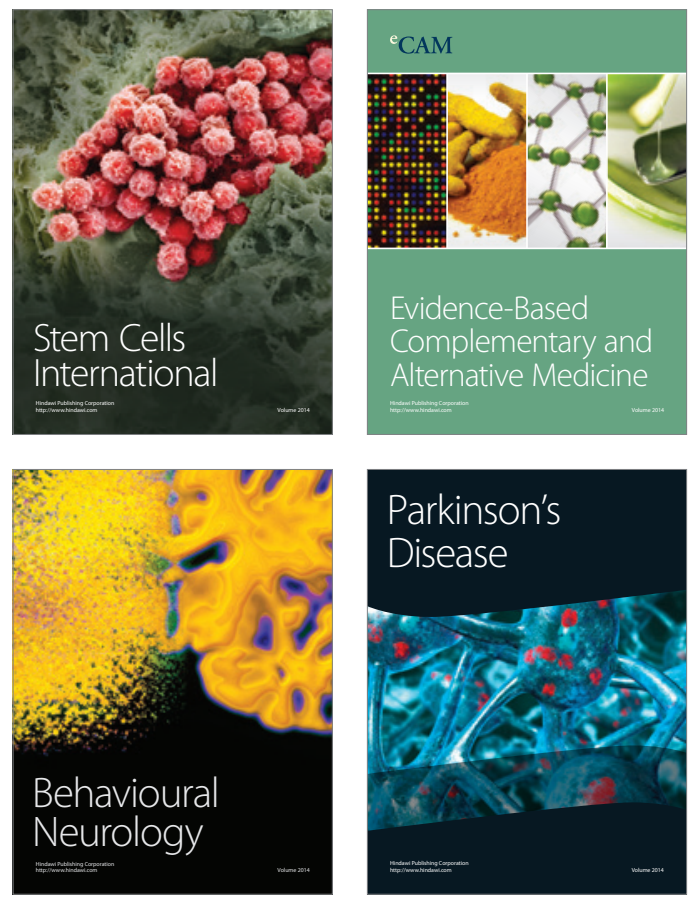
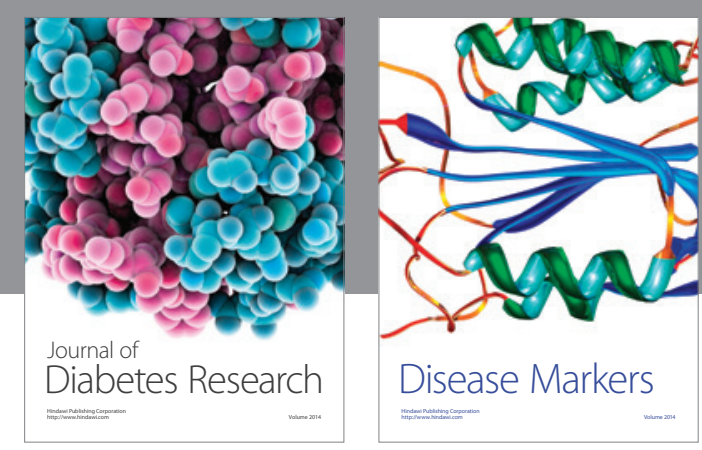

Disease Markers
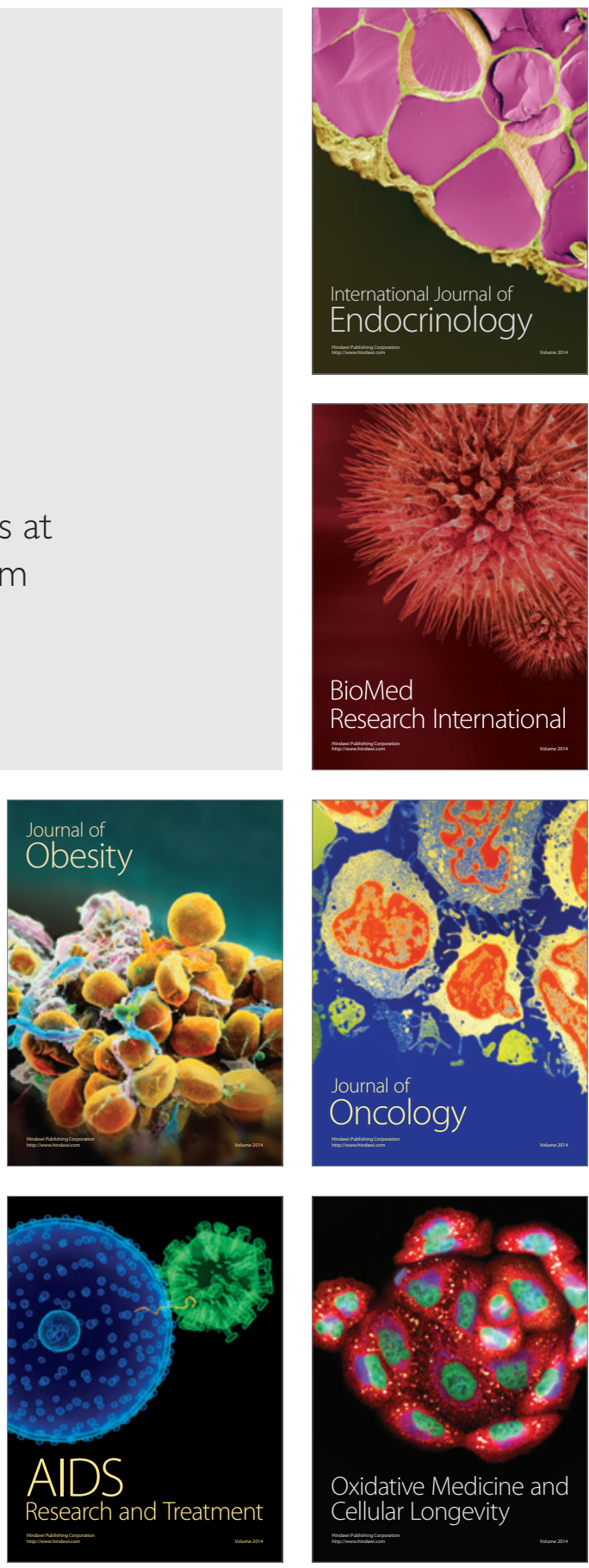